\title{
Tecnologias Computacionais como Práticas Motivacionais no Ensino Médio
}

\section{Luciana Bolan Frigo, Pamela Cardoso, Joice Preuss Cardoso, Caroline Fontana, Amanda Irizaga, Natália Victory, ElianePozzebon, Olga Yevseyeva}

Laboratório de Tecnologias Educacionais- Universidade Federal de Santa Catarina (UFSC)

Rodovia Jorge Lacerda (SC 449), km 35,4- 88.900-000 - Araranguá - SC - Brazil

luciana.frigo,eliane.pozzebon, yveseyeva.olga@ufsc.br

\begin{abstract}
This paper describes a set of workshops for high school students. These workshops introduce different computational tools arousing interests in in undergraduate technological areas. The students will look for knowledge in history, geography, physics, mathematics, and arts and apply them in game development, programming at robotic kits, etc.
\end{abstract}

Resumo. Este artigo descreve um conjunto de oficinas realizadas para alunas do ensino médio. Estas oficinas introduzem diferentes ferramentas computacionais, possibilitando despertar o interesse destas nos cursos superiores de áreas tecnológicas. As alunas deverão buscar conhecimentos nas diversas disciplinas como história, geografia, física, matemática, artes e aplicá-los no desenvolvimento de jogos, na programação dos kits robóticos, etc.

Palavras-chave: ensino médio, informática na educação, práticas educacionais

\section{Introdução}

Este artigo descreve um projeto de extensão universitária cujo objetivo é levar para escolas públicas de ensino médio, oficinas de informática que enriquecem e favorecem o processo de ensino aprendizagem. Estas ferramentas desenvolvem o raciocínio lógico e possibilitam situações para a resolução de problemas.

A ideia é bastante desafiadora, pois as alunas deverão buscar conhecimentos nas diversas disciplinas como história, geografia, física, matemática, artes e aplicá-los no desenvolvimento de jogos, na programação dos kits robóticos, etc. Estas alunas terão a oportunidade de experimentar atividades que sejam inerentes à atuação profissional em áreas relacionadas com as tecnologias computacionais, repensando e criticando o mito de que esta seja uma área dura e complexa e, mostrando que com um pouco de criatividade e bastante dedicação serão capazes de alcançar seus objetivos. Além de motivar as alunas para um papel mais ativo no processo de ensino-aprendizagem, este tipo de atividade pode ainda atrair um número maior de meninas para os cursos superiores de engenharias e áreas afins. Estas áreas dependem de profissionais capacitadas para atuarem nas suas especialidades. A seção 2 descreve como são organizadas e realizadas as principais oficinas ofertadas pelo projeto. A seção 3 apresenta alguns resultados deste projeto. 


\section{Materiais e Métodos}

As principais atividades do projeto são realizadas na forma de oficinas, cujo objetivo é o de levar estudantes do ensino médio ao laboratório de informática estimulando o uso de diferentes ferramentas computacionais de apoio à construção do conhecimento.

Para este projeto piloto, 30 alunas foram selecionadas a partir da aplicação de um questionário com objetivo de verificar o perfil das mesmas, tendo como foco a aptidão ou apreciação das disciplinas de matemática e física. Este projeto está no contexto de atrair mais mulheres para os cursos superiores relacionados às áreas de engenharias e tecnologias computacionais.

As oficinas acontecem em laboratórios de informática, com aulas expositivas, sempre buscando o envolvimento e a participação das estudantes, com muitas atividades práticas. São oficinas curtas com aproximadamente 3 h de duração.

\subsection{Podcasting}

A oficina de podcasting, conforme Figura 1, tem como principal objetivo permitir a criação de conteúdo multimídia, proporcionando um primeiro contato amigável com a área computacional.

Foi feita uma tradução e adaptação do curso "Digigirlz" fornecido pela Microsoft [Microsoft, 2013]. Este foi dividido em etapas:

a) Introdução: este tópico apresenta a origem do podcast, as características e os tipos. São apresentados alguns podcasts comerciais distribuídos gratuitamente na web para que as alunas se familiarizem com o assunto;

b) Pré-produção: consiste na abordagem dos elementos que devem ser pensados antes da construção do podcast, bem como um roteiro.

c) Produção: nesta etapa inicia a parte prática, onde as estudantes aprendem como gravar o seu podcast.

d) Pós-produção: além de criar o seu próprio conteúdo, elas aprendem a disponibilizá-lo na web para compartilhar com os seus amigos, por exemplo. 


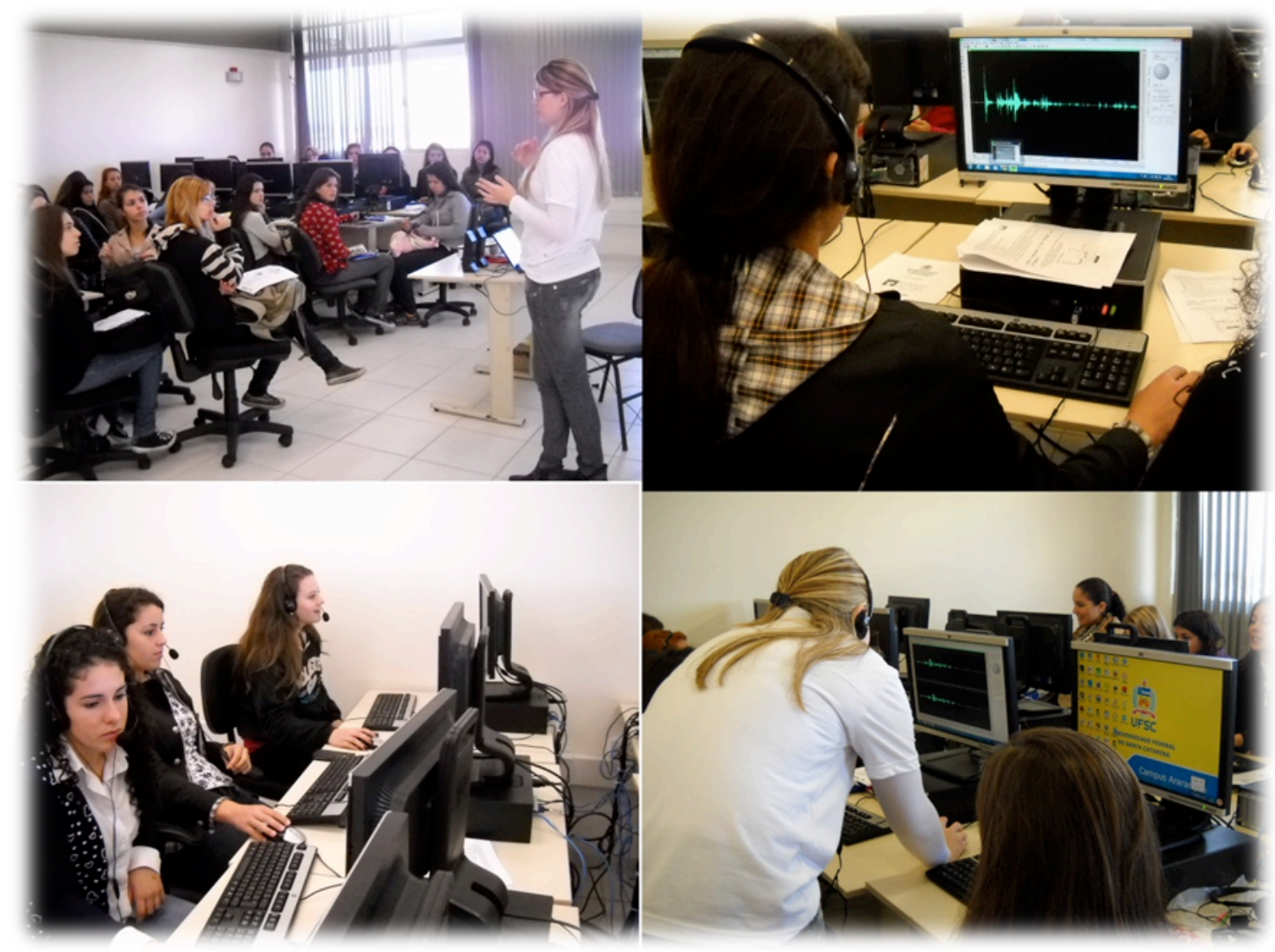

Figura 1. Oficina de Podcasting

\subsection{Oficina de construção de páginas Web}

O desenvolvimento de páginas web pode servir estimula a criatividade e serve como uma forma de aproximação do curso com atividades rotineiras, pois a maioria destas meninas tem o hábito de acessar páginas e blogs para pesquisar sobre assuntos relacionados ao processo de ensino-aprendizagem ou simplesmente para seu entretenimento.

Para a criação das páginas adota-se a linguagem HTML (HyperText Markup Language). Essa é uma linguagem de marcação e interpretada pelos navegadores, sendo assim, possível visualizar as formatações aplicadas.

No curso são abordados alguns temas introdutórios de como, por exemplo, um site pode ser um meio de comunicação eficiente. A seguir, é apresentado o antes e depois de alguns sites bastante conhecidos, para que as alunas constatem a importância e influencia da estética na popularidade de uma página web.

Na sequência é apresentado o conteúdo mais técnico, descrevendo de forma didática o funcionamento do tráfego de informações na internet, assim como, as trocas de dados 
entre cliente e servidor funcionam e o porquê da utilização da linguagem HTML, como ilustrado na figura 2 .

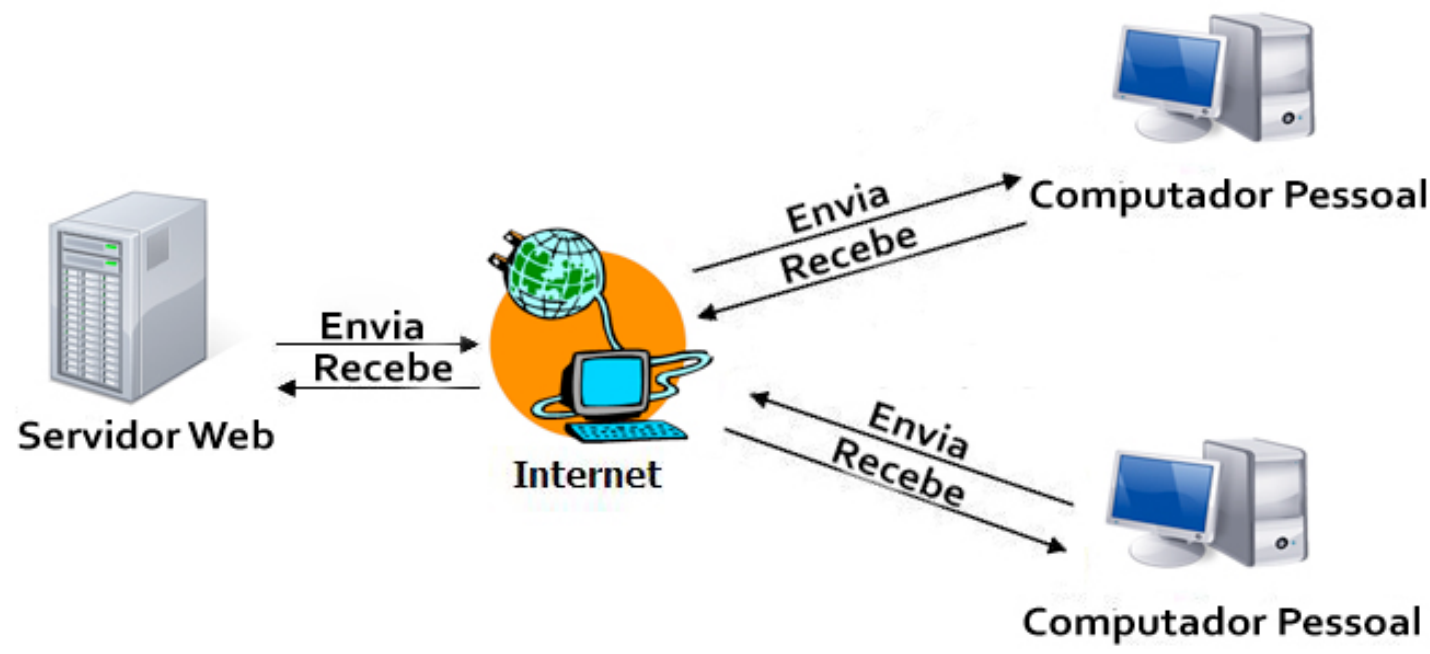

Figura 2. Cliente - Servidor

Realizada esta introdução, inicia-se a etapa de ensino da programação da linguagem. De acordo com [Sancho, 1997 apud THOBIAS,2000] a programação pedagógica através da verificação de hipóteses, da tomada de decisões e a conceituação, estimula a aprendizagem por descobrimento e a resolução de problemas. Pelo fato da programação no ensino médio ainda ser uma novidade no Brasil, a maioria das meninas nunca tinham programado. Trabalha-se aspectos referentes a digitação e configuração de textos, a aplicação de imagens ao código e a adição de link ao texto.

É apresentada uma explanação referente às opções de hospedagem gratuita da página. Com o auxílio do software para a transferência de arquivos para o servidor de páginas é possível transmitir as páginas elaboradas durante a aula.

As alunas expressaram grande interesse e curiosidade durante o curso. Na avaliação de satisfação aplicada após a conclusão desta oficina, pode-se comprovar isso, pois $100 \%$ das meninas responderam que gostaram do curso, com comentários bastante positivos. Em um dos depoimentos, gravado em vídeo, uma aluna do curso comentou que está disseminando o conhecimento aprendido passando os conceitos e ferramentas para os irmãos.

\subsection{Kit de Robótica Educacional}

A oficina de robótica tem como objetivo permitir que as alunas tenham a oportunidade de montar e programar seu próprio robô, bem como controlá-lo com a utilização de um computador pessoal e softwares adequados. Tudo isso, de uma forma positiva e divertida, tornando-se acessível os princípios de robótica e tecnologia as alunas.

A principal razão para utilizar dispositivos robóticos como proposta de ensinoaprendizagem é a construção do conhecimento. Ao utilizar um kit de robótica educacional, o foco não é apenas ensinar tecnologia e artefatos robóticos em si, mas também de aplicar a robótica no processo de ensino-aprendizagem [Silva, 2009]. Ao 
criar um robô a aluna atua de forma lógica e organizada, elaborando hipóteses, estabelecendo conexões entre os conhecimentos e investigando possíveis e diferentes soluções para um mesmo problema.

A utilização da robótica educacional pode contribuir positivamente em diversos aspectos pedagógicos, dentre eles pode-se destacar os seguintes [Zilli,2004]: estimular a criatividade, o raciocínio e a lógica na construção de algoritmos e programas para o controle de mecanismos, favorecer a interdisciplinaridade, aprimorar a motricidade com a execução de trabalhos manuais, incentivar a leitura, a exploração e a investigação, estimular o hábito do trabalho organizado, uma vez que a aluna deverá planejar, construir e avaliar seu projeto, bem como aprimorar a concentração, a disciplina e a persistência.

Para ensinar robótica é necessário o uso de equipamentos que favoreçam o contato das alunas com o planejamento, a construção e o controle de robôs. De acordo com a faixa etária e o contexto pedagógico que se deseja trabalhar, deve-se escolher o kit de robótica educacional adequado. Dentro deste contexto, para realização da oficina de robótica, são utilizados kits de robótica educacionais (Figura 3), da linha Lego Mindstorms ${ }^{\circledR}$ NXT 2.0, aliado ao seu software próprio chamado NXT-G (uma interface para controle e programação de dispositivos robóticos), que se baseia em uma linguagem de programação visual, com ícones intuitivos projetados para uma fácil introdução à programação para novos usuários e usuários experientes.

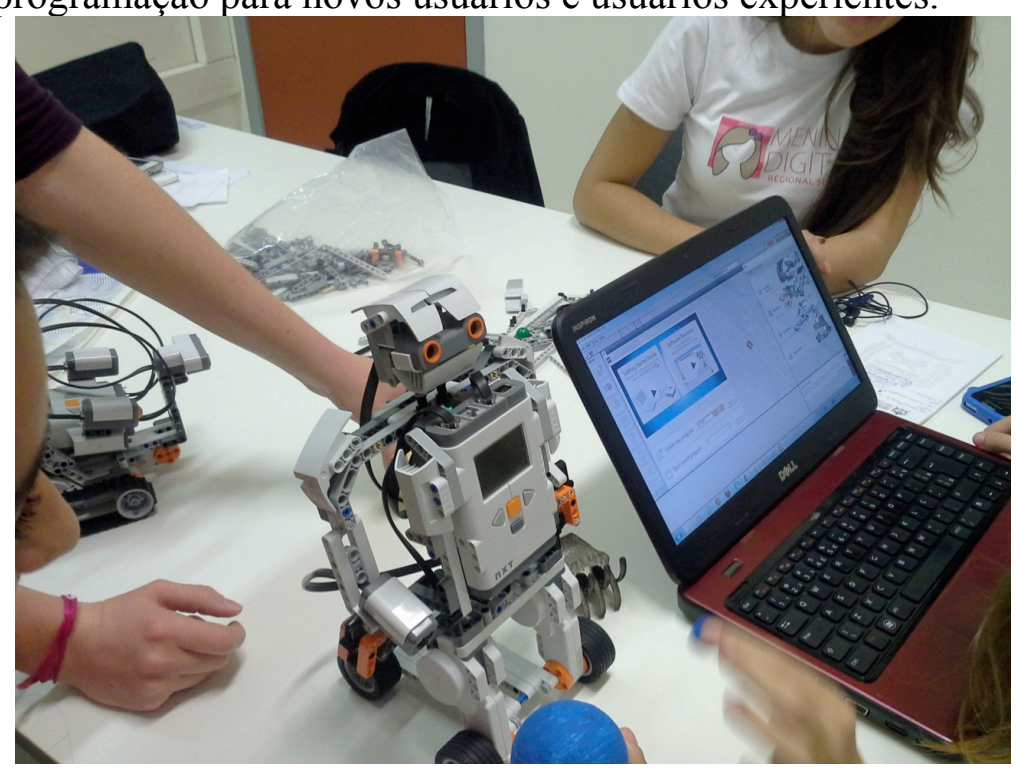

Figura 3. Programando com Kit robótico educacional

O Kit Lego Mindstorms ${ }^{\circledR}$ é composto por 619 elementos, que permitem a criação de diversos tipos de robôs (Figura 3). Dentre os elementos do kit, há um microcomputador que atua como o cérebro do robô, ou seja, nele ficam armazenadas as instruções (algoritmos) para controle do robô, onde são conectados 7 cabos para ligar os motores e os sensores em portas específicas. Além disso, o kit possui 3 motores, 2 sensores de toque que possibilitam ao robô "sentir", 1 sensor ultrassônico que permite a detecção de movimentos, 1 sensor de cor, que é capaz de detectar diferentes cores, além 
de diversos tipos de peças para construção de robôs simples e diversificados, passíveis de executar funções básicas pré-programadas no software.

Durante a realização da oficina de robótica, cada grupo de alunas recebe um kit de Lego Mindstorms ${ }^{\circledR}$, um computador com o software NXT-G devidamente instalado. Uma apostila é fornecida para cada aluna com instruções de montagem, programação e controle do robô. Dessa forma, além da aprendizagem formal, também é criado um ambiente de trabalho em equipe, que contribui para a superação de limites instigando as alunas a desenvolverem diferentes habilidades como de argumentação e contra argumentação, através da exposição de opiniões e conhecimentos.

No primeiro contato com as alunas, as monitoras explicam o que é robótica, e as atividades que cada equipe irá desempenhar, com o propósito de despertar a curiosidade das alunas. Durante a realização da oficina, as atividades dos grupos são acompanhadas pelas monitoras, que tem oportunidade de conhecer cada membro da equipe, o potencial e as limitações de cada uma podendo assim auxiliar no que for necessário.

Com tudo isso, a oficina de robótica mostra-se capaz de despertar na aluna interesse em ingressar no curso superior de engenharia de computação e áreas afins, além de proporcionar aprendizado e contribuir para diversos aspectos pedagógicos.

\subsection{Desenvolvimento de Jogos}

Buscando explorar a aproximação das alunas de ensino médio com o mundo dos jogos, a oficina de iniciação ao desenvolvimento de jogos foi planejada. Para tal, foi utilizado o Kodu [Microsoft, 2013], uma ferramenta de programação visual, desenvolvida especificamente para a criação de jogos.

O KODU foi criado pela Microsoft apenas para XBOX 360, tendo mais tarde, uma versão para computadores pessoais com a finalidade de incentivar crianças a partir de 8 anos a programarem. Apesar de ter sido desenvolvido para crianças, o KODU é uma ferramenta atrativa para adolescentes, afinal, com ela é possível começar a entender a lógica essencial para o desenvolvimento de um jogo. A plataforma é intuitiva e divertida.

Os jogos são desenvolvidos em 3D, e qualquer um pode disponibilizar seu jogo criado na comunidade, além de poder editar os jogos de outros usuários. Desta forma, ao mesmo tempo em que o usuário colabora com seus jogos, também aprende.

A oficina está organizada da seguinte forma: (i) há monitoras para retirar dúvidas dentro de sala e uma monitora que comanda a oficina; (ii) cada aluna possui um computador com a plataforma instalada; (iii) a oficina tem como ideal, ministrar aulas dinâmicas, para facilitar o aprendizado das alunas; (iv) a monitora faz uma breve descrição sobre a plataforma, e em poucos minutos já faz com que as alunas interajam com o KODU; (v) a cada passo explicado pela monitora, as alunas devem acompanhar e executar os mesmos passos em seu computador; (vi) ao final da oficina, é proposto um desafio as alunas, para que mostrem o que foi feito e incrementem o jogo, a fim de demonstrar suas habilidades com a ferramenta. 


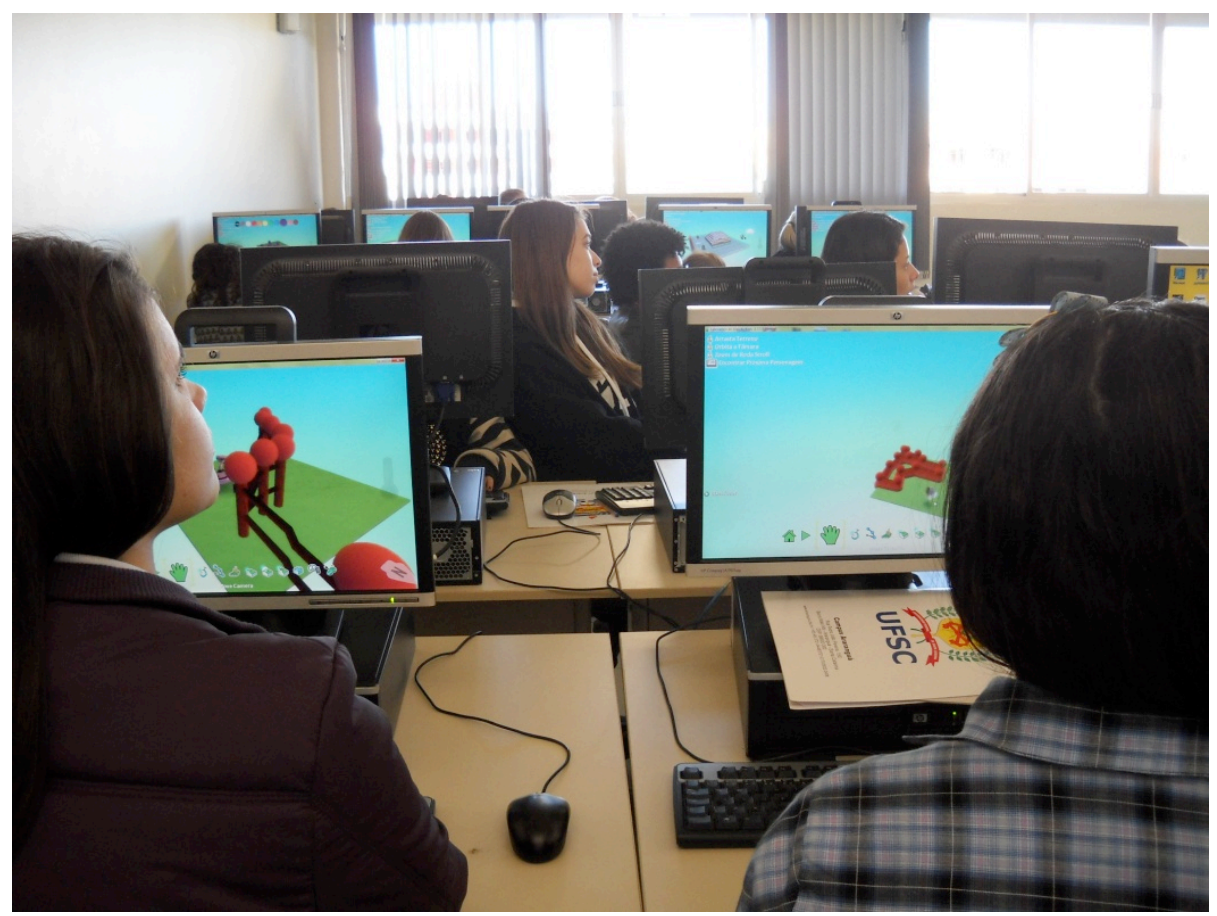

Figura 4. Oficina de desenvolvimento de jogos

Como citado anteriormente, o KODU pode ser um aliado complementar ao ensino fundamental e médio, principalmente no incentivo ao raciocínio lógico e criatividade. E é necessário frisar que, cada um tem seu tempo de aprendizagem e é necessário respeitar este tempo.

\section{Resultados}

As alunas usam tecnologias computacionais no seu dia a dia como forma de entretenimento e fazer com que esse entretenimento se torne também um momento de troca de conhecimento e aperfeiçoamento dos assuntos abordados em sala de aula é uma forma de instigá-las a correlacionarem e solidificarem estes conhecimentos. O desenvolvimento de jogos, por exemplo, desafia a aluna que se envolve com a proposta e busca em suas experiências subsídios para construir sua concepção de jogo. Outro aspecto a ser ressaltado é que as atividades incentivam a integração entre as alunas, melhorando aspectos de socialização, com as atividades desenvolvidas em equipe ou ainda para a troca de conhecimento entre as equipes, habilidades de fundamental importância, para o futuro profissional que está em formação.

Este projeto tem como foco permitir que alunas do ensino médio se familiarizem com as tecnologias computacionais e principalmente se sintam parte deste mundo culturalmente caracterizado como sendo masculino. Desta maneira, elas podem se sentir parte integrante da sociedade como um todo, onde a mulher não é excluída de atuar em determinada área simplesmente por ser do sexo feminino. E se ela gostar e quiser desenvolver tais habilidades escolher um curso superior ligado às áreas de engenharia ou computação. 


\section{Agradecimento}

Este projeto tem o apoio CNPq/VALE S.A. N ${ }^{o}$ 05/2012 - Forma-Engenharia. Agradecemos também a EEB Prof. Maria Garcia Pessi, da cidade de Araranguá/SC grande parceira nos projetos de extensão com a UFSC.

\section{Referências}

MICROSOFT. Global Diversity and Inclusion (2013). Disponível em:

<http://www.microsoft.com/en-us/diversity/programs/digigirlz/default.aspx > Acesso em: 15 agosto 2013

SILVA, Alzira Ferreira da.(2009) RoboEduc: Uma Metodologia de Aprendizado com Robótica Educacional. 2009. 133 f. Tese (Doutorado em Engenharia da Computação) - Programa de Pós-Graduação em Ciências e Engenharia Elétrica, Universidade Federal do Rio Grande do Norte, Natal. Disponível em: $<$ http://ftp.ufrn.br/pub/biblioteca/ext/bdtd/AlziraFS.pdf>. Acesso em: 15 agosto 2013.

THOBIAS, M. A. L. S.9 (2000), A internet e o ensino de ciências. Dissertação de mestrado, UNESP.

ZILLI, Silvana do Rocio (2004). A Robótica Educacional no Ensino Fundamental: Perspectivas e Prática. Dissertação de Mestrado - Programa de Pós-Graduação em Engenharia de Produção da Universidade Federal de Santa Catarina, Florianópolis. Disponível

em: $<$ https://repositorio.ufsc.br/bitstream/handle/123456789/86930/224814.pdf?sequence=1 >. Acesso em:15 agosto 2013. 